\title{
Effect of EphA7 Silencing on Proliferation, Invasion and Apoptosis in Human Laryngeal Cancer Cell Lines Hep-2 and AMC-HN-8
}

Cheng Xiang Yuanjing Lv Yanjie Wei Jing Wei Susheng Miao Xionghui Mao Xin Gu Kaibin Song Shenshan Jia

Department of Head and Neck Surgery, the Third Affiliated Hospital of Harbin Medical University, Harbin China

\section{Key Words}

Laryngeal squamous cell carcinoma • EphA7 • siRNA • Proliferation • Invasion • Apoptosis

\begin{abstract}
Aims: This study aimed to investigate the expression of EphA7 in human laryngeal squamous cell carcinoma (LSCC) tissues and disclose the potential roles and molecular mechanisms of EphA7 in LSCC. Methods: In the present study, we examined EphA7 expression and its function and mechanism in LSCC. EphA7 expression levels were investigated by quantitative real-time PCR (qRT-PCR), western blotting, and immunohistochemistry in a panel of 35 LSCC patient cases. To investigate the potential mechanism of EphA7 in human laryngeal cancer, we employed EphA7 siRNA to knockdown EphA7 expression in LSCC cell line Hep-2 and AMCHN-8. Subsequently, MTT, TUNEL, qRT-PCR, and western blotting were performed to disclose the roles of EphA7 on proliferation, invasion and migration, and apoptosis in LSCC cell line Hep-2 and AMC-HN-8. Results: Depletion of EphA7 remarkably inhibited the proliferation and invasion of Hep-2 and AMC-HN-8 cells in comparison to control and EphA7 siRNA negative control (NC)-transfected cells. TUNEL staining assay demonstrated that, compared with the control group, the rate of apoptosis in the EphA7 siRNA group was significantly increased. In addition, knockdown of EphA7 in Hep-2 or AMC-HN-8 cells markedly decreased the expression of EphA7 and PTEN, which could contribute to apoptosis. However, the bpV(phen), a PTEN inhibitor, could attenuate anti-proliferation and pro-apoptotic effects of EphA7 siRNA in Hep-2 and AMC-HN-8 cells. Conclusion: Up-regulation of EphA7 was observed in human LSCC samples and down-regulation of EphA7 effectively suppressed laryngeal carcinoma cell growth and promoted its apoptosis. Thus, EphA7 has a critical role in modulating cell growth and apoptosis, which serves as a potential therapeutic target in human LSCC.

Copyright (C) 2015 S. Karger AG, Basel

C. Xiang and Y. Lv contributed equally to this manuscript.

Shenshan Jia, MD, PhD

Department of Head and Neck Surgery, The Third Affiliated Hospital of Harbin Medical University Harbin, No. 150 Heping Rd. Nangang District, Harbin, 150081 (China) Tel.+86-150-0460-4121, E-Mail JiaSS@163.com
\end{abstract}

KARGER 125 


\section{Cellular Physiology Cell Physiol Biochem 2015;36:435-445 \\ \begin{tabular}{l|l} 
and Biochemistry Published online: May 11, 2015 & $\begin{array}{l}\text { C) 2015 S. Karger AG, Basel } \\
\text { www.karger.com/cpb }\end{array}$ \\
\hline
\end{tabular} \\ Xiang et al.: Effect of EphA7 Silencing on Human Laryngeal Cancer Cells}

\section{Introduction}

Laryngeal squamous cell carcinoma (LSCC) is one of the most common malignancies in the head and neck region, which is the $8^{\text {th }}$ most common cancer worldwide [1]. Although the therapeutic strategies of LSCC patients include surgery therapy, chemo-radiotherapy, gene therapy and immunotherapy, the therapeutic outcomes and the overall 5-year survival rate are still not satisfactory in recent years. It is well known that invasion and metastasis are two key reasons related to the 5-year survival of LSCC patients [2]. Thus, more powerful diagnostic strategies about early stage of LSCC have long been warranted. In addition, surgery might lead to complete or partial loss of vocal function and many patients have to maintain a tracheal cannula for life due to total laryngectomy. Therefore, a better understanding of the molecular mechanisms of LSCC progression and a new strategy for the treatment of LSCC are in urgent demand.

It has been indicated that conventional pathologic prognostic parameters are insufficient to accurately assess the clinical prognosis of LSCC patients. Moreover, biomarkers are believed to be beneficial not only in evaluating the prognosis but also in guiding personalized therapy for patients with cancer $[3,4]$. Therefore, it is necessary to search for potential biomarkers of human LSCC. The erythropoietin-producing hepatoma-amplified sequence (Eph) receptors are a large family of receptor tyrosine kinases comprising eight EphA and six EphB receptors in humans [5]. Recent studies unveiled the involvement of Eph-ephrin interaction in a variety of developmental processes including arterial-venous differentiation [6], cell migration [7] which results in compartmentalizing cell subpopulations in the developing tissue, and cell movement into the appropriate embryonic environment which may determine a particular cell fate and result in cell differentiation and patterning. Besides such physiological roles, recent studies have also demonstrated that many human malignancies are involved in dysregulated expression of Eph receptors, including up-regulation of ephrin-A1 or -B2 in melanoma [8], up-regulation of EphB2 in stomach cancer $[9,10]$ and in breast cancer [11], and up-regulation of EphA2 in prostate [12], breast [13], and esophageal cancers [14], some of which were shown to be associated with tumor invasion or tumor metastasis and therefore associated with poor prognosis. Conversely, mutational inactivation of EphB2 was detected in prostate [15] and colon cancers [16], suggesting tumor suppressor function of this Eph receptor in the relevant tumors.

EphA7 (formerly known as Mdk1/Ebk/Ehk), is a member of the largest known subgroup of receptor tyrosine kinases, which is highly conserved in vertebrates from fish to human [17]. EphA7 is widely expressed in embryonic tissues, especially developing central nervous system [18]. A previous study disclosed that the EphA7 receptor regulates apoptosis during early brain development. In addition, Park et al. demonstrated that the EphA7 receptor interacts with death receptors such as tumor necrosis factor receptor 1 (TNFR1) to decrease cell viability [19]. They disclosed that ephrinA5 stimulates EphA7 to activate the TNFR1mediated apoptotic signaling pathway. This result suggested that a distinct multi-protein complex comprising ephrinA5, EphA7, and TNFR1 may constitute a platform for inducing caspase-dependent apoptotic cell death [19]. Moreover, recent studies showed that EphA7 has also been described as a tumor suppressor. In a recent study, Wendel et al. have identified a soluble variant of the ephrin receptor A7 as a tumor suppressor that is lost in lymphoma [20]. They also developed antibody-based delivery to restore this tumor suppressor to the cancer cells in situ [20].

The aim of the present study was to disclose the expression of EphA7 in human laryngeal squamous cell carcinoma (LSCC) tissues and to demonstrate the potential roles and molecular mechanisms of EphA7 in LSCC. To this end, we evaluated the exporession level of EphA7 in a panel of 35 LSCC patient cases, which was investigated by immunohistochemistry, qRTPCR and western blotting assay. And then we employed EphA7 siRNA to knockdown EphA7 expression in LSCC cell line Hep-2 and AMC-HN-8 to explore the role of the EphA7 in the regulation of Hep-2 or AMC-HN-8 cells apoptosis via PTEN/Akt signalling pathway in vitro. 


\section{Cellular Physiology Cell Physiol Biochem 2015;36:435-445 \begin{tabular}{l|l|l}
\hline DOI: 10.1159/000430110 & (C)15 S. Karger AG, Basel
\end{tabular} and Biochemistry Published online: May 11, $2015 \quad$ www.karger.com/cpb \\ Xiang et al.: Effect of EphA7 Silencing on Human Laryngeal Cancer Cells}

\section{Material and Methods}

\section{Antibodies}

EphA7 rabbit monoclonal (Santa Cruz, USA), PTEN rabbit monoclonal (Cell Signaling Technologies Inc., USA), Akt and p-Akt rabbit monoclonal (Santa Cruz, USA), Bax rabbit monoclonal (Cell Signaling Technologies Inc., USA), Bcl-2 rabbit monoclonal (Cell Signaling Technologies Inc., USA), Caspase-3 rabbit monoclonal (Cell Signaling Technologies Inc., USA), GAPDH rabbit monoclonal (Abcam, USA).

\section{Patient samples}

We obtained the human tissues from the Third Affiliated Hospital of Harbin Medical University under the procedures approved by the Ethnic Committee for Use of Human Samples of the Harbin Medical University. Informed consent was obtained from all subjects. All specimens were coded and deidentified. The specimens comprised a panel of 35 LSCC patient cases obtained during surgical procedures which were immediately stored in liquid nitrogen or fixed in formalin.

\section{Immunohistochemistry}

Cancer tissues and corresponding adjacent normal tissues were collected during surgery and were subsequently fixed in formalin and embedded in paraffin, which were sequentially sectioned into $4 \mu \mathrm{m}$ each. After deparaffinization and rehydration, sections were treated with $0.3 \% \mathrm{H}_{2} \mathrm{O}_{2}$, and then were incubated with $10 \%$ normal goat serum. Antigen retrieval was performed using EDTA (pH 8.0) at $100^{\circ} \mathrm{C}$ for $20 \mathrm{~min}$. Sections were then washed, and incubated with the EphA7 primary antibodies at $4^{\circ} \mathrm{C}$ overnight. Sections were subsequently incubated at $37^{\circ} \mathrm{C}$ for $45 \mathrm{~min}$ before being washed and incubated with secondary antibodies at room temperature. After $1 \mathrm{~h}$, sections were washed and incubated with diaminobenzidine tetrachloride for $10 \mathrm{~min}$. Sections were also counterstained with haematoxylin. Negative controls were prepared in parallel and were incubated with PBS instead of the primary antibodies.

\section{Cell culture}

The Hep-2 cells and AMC-HN-8 cells used in this study were purchased from American Type Culture Collection (ATCC, Manassas, VA). Hep-2 cells were cultured in Dulbecco's Modified Eagle Medium (DMEM) and AMC-HN-8 cells were cultured in RPMI-1640. The cultures were supplemented with $10 \%$ fetal bovine serum and $100 \mu \mathrm{g} / \mathrm{ml}$ penicillin/streptomycin.

\section{Small interfering RNA (siRNA) and transfection}

The following EphA7 siRNA sequence was obtained from GenePharma (Shanghai, China): 5'-GUGGGAAGUUAUGUCUUAUTTAUAAGACAUAACUUC CCACTT-3'. As a control, the following scramble siRNA sequence was also used: 5'-UUCUCCGAACGUGUCACGUTTACGUGACACGUCCGGAGAATT-3'. The cells were transfected with siRNAs using Lipofectamine reagent (Invitrogen Life Technologies, USA) according to the manufacturer's instructions and further incubated for $48 \mathrm{~h}$ prior to being used in the subsequent experiments. In the EphA7 siRNA+ bpV(phen) group, the Hep-2 cells or AMC-HN-8 cells were treated with $\mathrm{bpV}$ (phen) at the dose of $10 \mathrm{uM}$ for $24 \mathrm{~h}$ after transfection with EphA7 siRNA for $24 \mathrm{~h}$.

\section{Quantitative reverse transcription-PCR ( $q R T-P C R)$}

After the experimental treatment, total RNA from human laryngeal squamous cell cancinoma was isolated using Trizol reagent (Invitrogen, USA) according to manufacturer's protocol. Total RNA $(0.5 \mu \mathrm{g})$ was then reverse transcribed using High-Capacity cDNA Reverse Transcription Kit (Applied Biosystems, USA) to obtain cDNA. The RNA levels of EphA7 was determined using SYBR Green I incorporation method on ABI 7500 fast Real Time PCR system (Applied Biosystems, USA), with GAPDH as an internal control. The sequences of primers were as follows: EphA7-F:CTAATGTTGGATTGTTGGCAAAAG; EphA7-R:TTGATCCAGAAGAG GGCTTATTG; GAPDH-F: AAGAAGGTGGTGAAGCAGGC; GAPDH-R: TCCAC C ACCCAGTTGCTGTA.

\section{Cell proliferation assay evaluation using MTT test}

Hep-2 cells or AMC-HN-8 cells were plated in 96-well plates and treated with saline, EphA7 siRNA or EphA7 siRNA negative control (NC) respectively. After the treatment period, the serum-free medium was removed, and then the cells were cultured with regular culture medium for another $48 \mathrm{~h}$. To monitor 


\section{Cellular Physiology Cell Physiol Biochem 2015;36:435-445 \begin{tabular}{l|l|l} 
DOI: 10.1159/000430110 & (C) 2015 S. Karger AG, Basel
\end{tabular} \begin{tabular}{l|l|l|l|l} 
and Biochemistry Published online: May 11, 2015 & www.karger.com/cpb
\end{tabular} \\ Xiang et al.: Effect of EphA7 Silencing on Human Laryngeal Cancer Cells}

cell survival, Hep-2 cells or AMC-HN-8 cells were incubated for $4 \mathrm{~h}$ with $0.5 \mathrm{mg} / \mathrm{mL}$ of MTT (Sigma), and resuspended in $150 \mu \mathrm{L}$ of DMSO (Sigma). Absorbance was recorded at $490 \mathrm{~nm}$ using an Easy Reader 340 AT (SLT-Lab Instruments). Results are presented as percentage of survival taking the control as 100\% survival. Experiments were repeated four times.

\section{TUNEL assay}

Apoptotic Hep-2 cells or AMC-HN-8 cells in different group were detected using a terminal dUTP nick end-labeling (TUNEL) assay as previously described [21]. The TUNEL staining was detected using the in situ cell death detection kit (Roche) according to the manufacturer's protocol. Sections were also co-stained with 4', 6-diamidino-2-phenylindole (DAPI) (1:5 dilution, Invitrogen) for nuclei. The average of the TUNELpositive nuclei ratio in at least 10 representative microscopic fields was calculated to compare the apoptosis ratio within the different groups.

\section{Invasion assay}

Invasion assays were conducted using $8 \mu \mathrm{M}$ polyethylene terpthalate filters (BioCoat ${ }^{\mathrm{TM}}$ Matrigel Invasion Chambers, BD Pharmingen), as described earlier [22]. Hep-2 Cells or AMC-HN-8 cells (transfected with EphA7 siRNA or NC) were allowed to invade through matrigel coated filters for $16 \mathrm{~h}$ in a transwell. Cells invaded to the lower sides of the transwell, cells were fixed using $4 \%(\mathrm{w} / \mathrm{v})$ paraformaldehyde and stained using $0.05 \%$ crystal violet, and the cell number was counted as described before.

\section{Measurement of cell migration with transwell migration assay}

Transwell migration assay was used to measure cell migration. Nuclepore filters with $8 \mathrm{~nm}$ pore size (Corning Inc., Corning, NY, USA) were coated with type IV collagen (Sigma-Aldrich) overnight at $37^{\circ} \mathrm{C}$ before the test. Hep- 2 cells $\left(5 \times 10^{4}\right)$ or AMC-HN-8 cells were added to the upper chambers while the lower chambers were filled with tacrolimus $\left(0,10^{1}, 10^{2}, 10^{3}, 10^{4} \mathrm{nmol} / \mathrm{L}\right)$. After 48 hours of incubation, the cells on the upper side were scraped off, and the cells that migrated to the lower side of the membrane were fixed with $4 \%$ paraformaldehyde, then stained with $0.1 \%$ crystal violet for 30 minutes at room temperature, and washed three times with PBS. The migrated cells in the lower side of the membrane were observed and photographed under inverted microscope (Nikon, Japan). Three randomly selected fields were photographed and the migrated cells were counted.

\section{Western blot analysis}

The total amount of protein was extracted from the human LSCC tissue or cell lines Hep-2 and AMCHN-8 for immunoblotting analysis. Briefly, the protein concentrations were determined with a bicinchoninic acid protein assay kit using bovine serum albumin as the standard. Equal amounts of protein $(100 \mu \mathrm{g})$ were fractionated by SDS-PAGE and blotted to PVDF membrane (Millipore, Bedford, MA). The blots were blocked by $5 \%$ non-fat milk dissolved in PBS for $2 \mathrm{~h}$, then probed overnight at $4^{\circ} \mathrm{C}$ with the following primary antibodies: EphA7 (1:1000 dilution), PTEN (1:1000 dilution), Total Akt (1:200 dilution), p-Akt (1:1000 dilution), Bax (1:1000 dilution), Bcl-2 (1:1000 dilution), Caspase-3 (1:500 dilution) and anti-GAPDH (1:500 dilution), all in 5\% milk TBST. Membranes were washed three times, 15 min each time, with PBS containing $0.5 \%$ Tween 20 (PBS-T) and incubated with secondary antibody (1:8000 dilution, Alexa Fluor® 700 goat anti-mouse IgG $(\mathrm{H}+\mathrm{L})$ or Alexa Fluor 800 goat anti-rabbit IgG $(\mathrm{H}+\mathrm{L})$, Invitrogen) in PBS at room temperature for $1 \mathrm{~h}$. Western blot bands were captured by using the Odyssey Infrared Imaging System (LICOR Biosciences, Lincoln, NE, USA) and quantified with Odyssey v1.2 software (LI-COR Biosciences, Lincoln, NE, USA) by measuring the band intensity (area×OD) in each group and normalizing to GAPDH as an internal control. Unless otherwise stated, western blot experiments were repeated four times.

\section{Statistical analysis}

All quantitative data are expressed as the mean \pm SEM and analysed by SPSS 13.0 software. Two-tailed unpaired Student's t-tests and one-way ANOVA were used for statistical evaluation of the data. $\mathrm{P}<0.05$ was considered as statistically significant. 
A

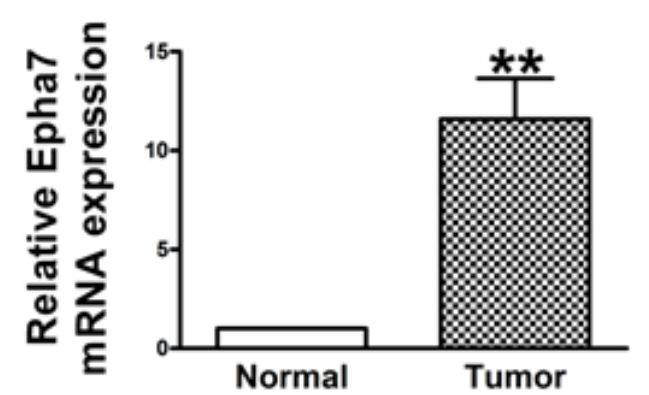

B

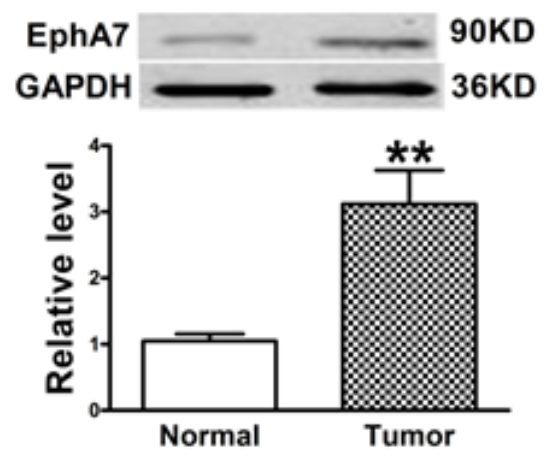

Fig. 1. Expression levels of EphA7 in LSCC samples. (A) mRNA level of EphA7 in normal and human LSCC samples; (B) Protein level of EphA7 in normal and human LSCC samples. Data are expressed as mean \pm SEM, $\mathrm{n}=35 ;{ }^{* *} \mathrm{P}<0.01$ vs Normal control.

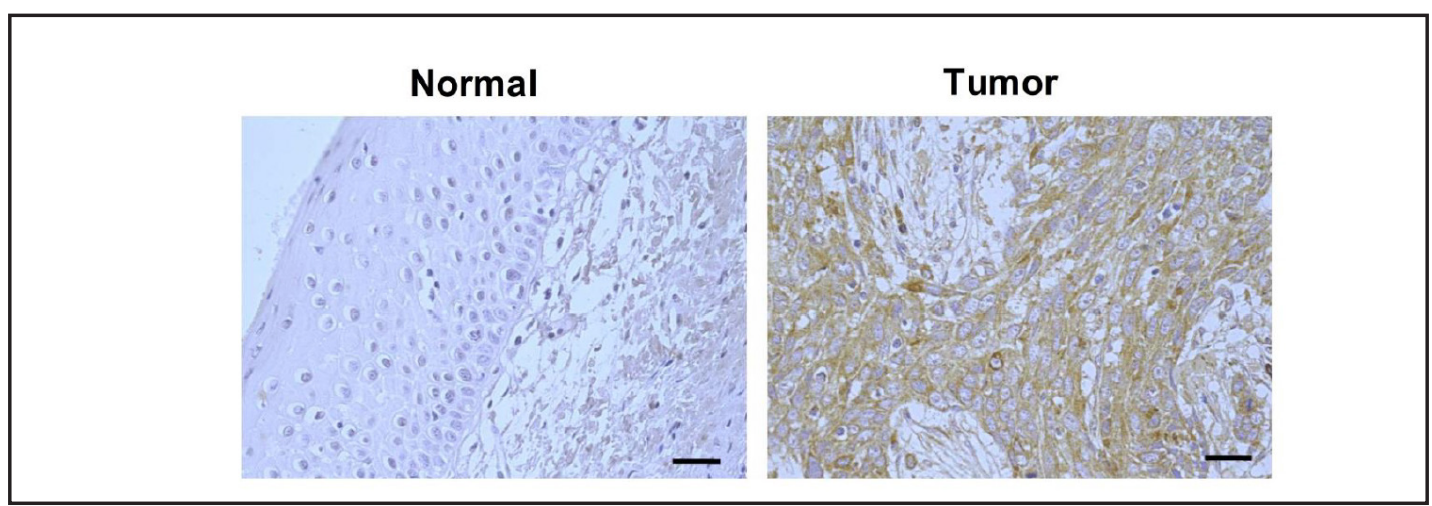

Fig. 2. EphA7expression as visualized by immunohistochemistry staining. Cells with brown staining in the nuclei or cytoplasm were classified as having low or high expression. (A) Negative expression of EphA7 in corresponding adjacent normal tissue. (B) High expression of EphA7 in human LSCC tissue (original magnification, $\times 400$ ). Bar $=100 \mu \mathrm{m}$.

\section{Results}

EphA7 is over-expressed in human LSCC in vivo

Real-time PCR and western blotting were used to determine the expression status of EphA7 for both LSCC tissue samples and matched normal tissue samples obtained from 35 patients diagnosed with LSCC. For the LSCC samples, the mean mRNA level for EphA7 was nearly 11 -fold higher than that of the corresponding matched samples (Fig. $1 \mathrm{~A})(\mathrm{P}<0.05)$. Moreover, the western blotting results also showed that EphA7 in LSCC samples was markedly higher than in normal tissue samples (Fig. 1B).

Consistent with the mRNA and protein levels detected for EphA7, immunohistochemistry assays detected stronger expression of EphA7 in tissue sections from LSCC sample and was expressed not only in the cell nuclei but also in the cytoplasm of tumor cells. In contrast, EphA7 immunohistochemical staining was negative in all 35 tissue sections from corresponding adjacent normal tissues (Fig. 2).

Knockdown of EphA7 inhibits proliferation and stimulates apoptosis of Hep-2 cells or AMC-HN-8 cells

As shown in Figure 3A, knockdown of EphA7 by EphA7 siRNA significantly inhibited Hep- 2 cells or AMC-HN-8 cells growth determined by MTT assay. These results indicate that EphA7 silencing is overall an effective inhibitor of Hep-2 cells (Fig. 3A) and AMC-HN-8 cells 


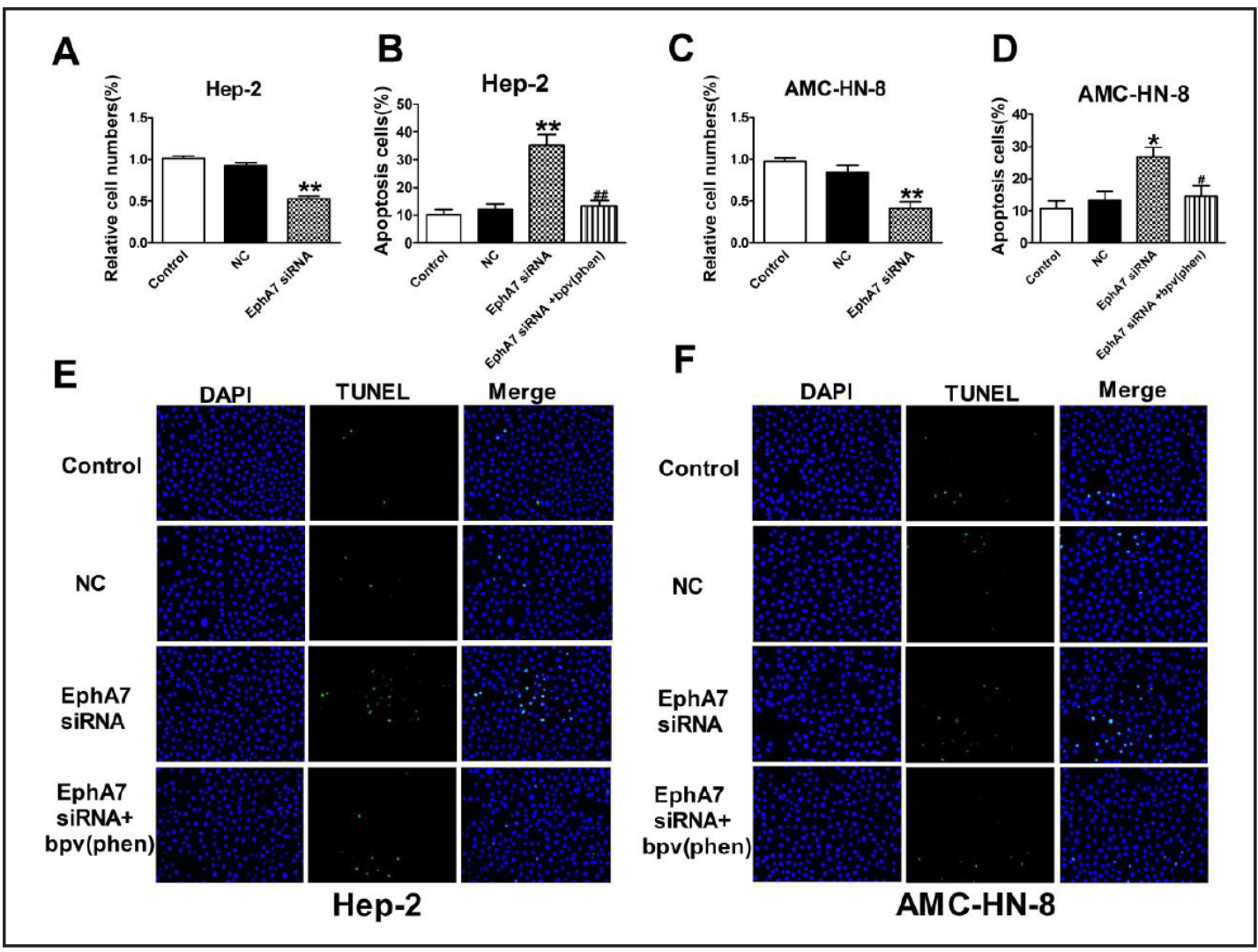

Fig. 3. Effects of EphA7 siRNA on the proliferation and apoptosis in Hep-2 or cells. (A) MTT assay of the Hep- 2 cells proliferation. Data are expressed as mean $\pm \mathrm{SEM}, \mathrm{n}=4,{ }^{* *} \mathrm{P}<0.01$ vs control; (B) The number of apoptotic Hep- 2 cells was determined by TUNEL assay. Data are expressed as mean \pm SEM, $n=10,{ }^{* *} \mathrm{P}<0.01$ vs control; "\# $\mathrm{P}<0.01$ vs EphA7 siRNA group; (C) MTT assay of the AMC-HN-8 cells proliferation. Data are expressed as mean \pm SEM, $n=4,{ }^{* *} \mathrm{P}<0.01$ vs control group; (D) The number of apoptotic AMC-HN-8 cells was determined by TUNEL assay. Data are expressed as mean \pm SEM, $n=10,{ }^{*} \mathrm{P}<0.05$ vs control group; ${ }^{\#} \mathrm{P}<0.05$ vs EphA7 siRNA group; (E) Apoptotic Hep-2 cells were determined by TUNEL staining and visualized at 200× magnification. (F) Apoptotic AMC-HN-8 cells were determined by TUNEL staining and visualized at $200 \times$ magnification. Green color is TUNEL staining representing apoptotic cell; blue color is the cell nucleus stained by DAPI.

(Fig. 3C) growth. To evaluate the extent of apoptosis in Hep-2 and AMC-HN-8 cells, apoptotic cells were stained using the TUNEL method. The number of apoptotic-positive cells was counted in a high-power field ( $\times 200$ magnification). A notable increase of apoptotic-positive Hep- 2 cells (Fig. 3B and 3E) or AMC-HN-8 cells (Fig. 3C and 3F) were observed in the EphA7 siRNA treatment group, compared with the control group $(\mathrm{P}<0.05)$. However, the negative control siRNA could not take the same effects (Fig. 3). However, bpV(phen), a PTEN inhibitor, could attenuate the pro-apoptotic function of EphA7 siRNA in Hep-2 (Fig. 3B and 3E) and AMC-HN-8 cells (Fig. 3D and 3F).

Downregulation of EphA7 suppresses the migration and invasion of Hep-2 cells or AMC$H N-8$ cells in vitro

As shown in Figure 4, compared with controls, the migratory capabilities of cells transfected with the EphA7 siRNA were reduced by approximately $33.78 \%$ for Hep-2 cells. However, cells in the EphA7 siRNA negative control group (52.43 \pm 3.35$)$ had the same migration ability as control (57.14 \pm 4.12 ) (Fig. 4C). To investigate whether EphA7 contributes to the invasive phenotype of Hep-2 cells, invasion assays were performed using 24-well

\section{KARGER}




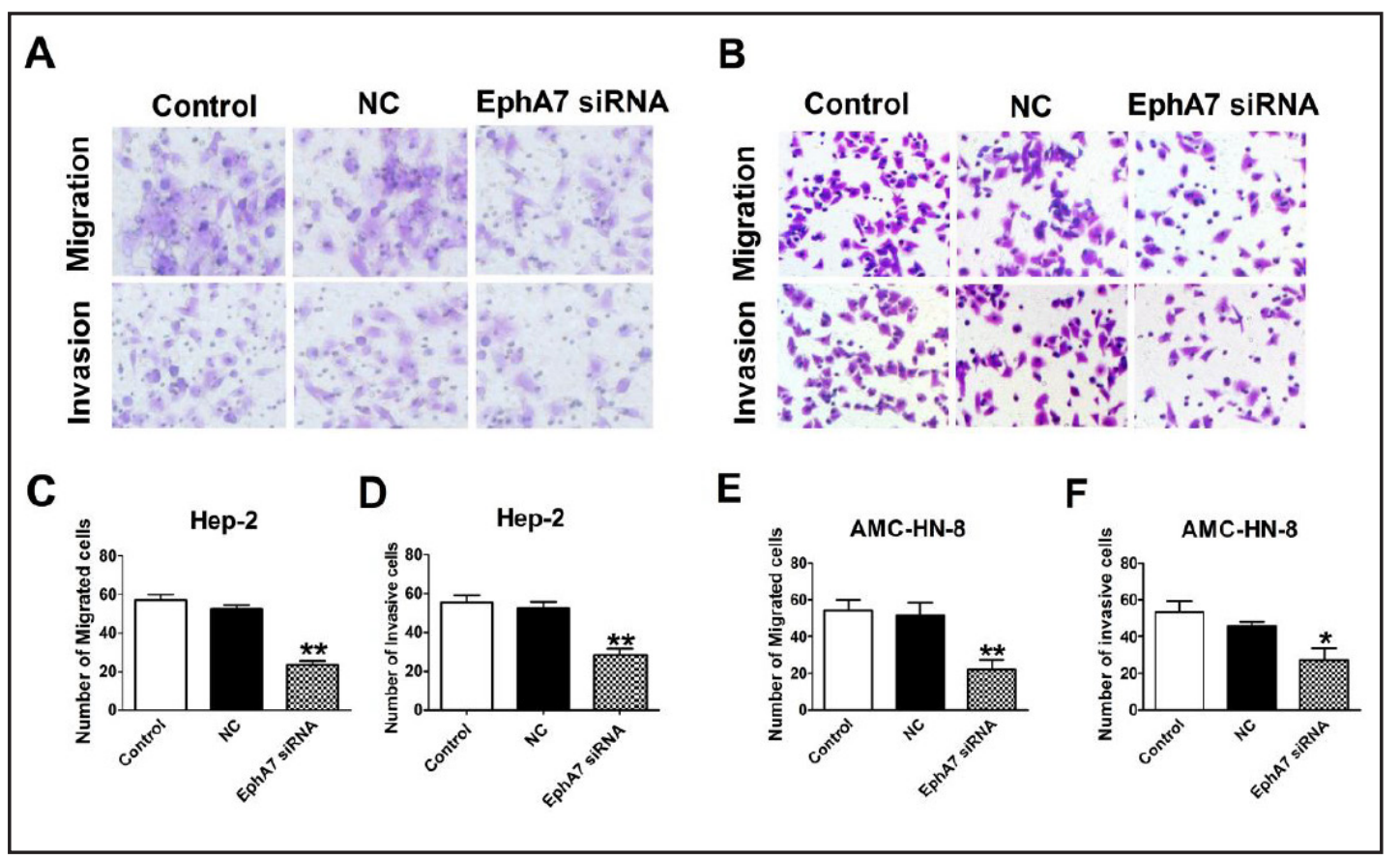

Fig. 4. EphA7 siRNA inhibits the migration and invasion of cultured Hep-2 or AMC-HN-8 cells. (A) Photographs represented the cells travelled through the membrane by Transwell assay and the cells passing through the Matrigel by Matrigel invasion assay (original magnification, $\times 200$ ). (B) The histogram showed the number of migrated cells. (C) The histogram showed the number of invaded cells. Data are expressed as mean \pm SEM, $n=3 ;{ }^{* *} \mathrm{P}<0.01$ vs Control.

Boyden chambers coated with Matrigel. As shown in Figure 4D, the number of EphA7 siRNAtreated Hep-2 cells exhibiting an invasive phenotype (28.2 \pm 4.49 ) was less than that observed for NC control-treated Hep-2 cells (52.28 \pm 5.07$)$ and untreated Hep-2 cells (55.57 \pm 5.32 ). These data strongly suggest that downregulation of EphA7 may mediate a reduction in the migration and invasion of Hep-2 cells.

In addition, we repeated the same experiments in AMC-HN-8 cells and we also found that downregulation of EphA7 might mediate a reduction in the migration (Fig. 4B and 4E) and invasion (Fig. 4F) of AMC-HN-8 cells.

Involvement of PTEN/AKT signal pathway in EphA7 siRNA-induced apoptosis in Hep-2 cells or AMC-HN-8 cells

Western blotting was used to measure expression levels of EphA7, PTEN, p-Akt and Akt in the Hep-2 cells transfected with EphA7 siRNA and EphA7 siRNA negative control. When Hep-2 cells were transfected with the EphA7 siRNA, lower levels of EphA7 were detected compared to cells transfected with the negative control siRNA or untransfected cells $(\mathrm{P}<0.05)$ (Fig. 5A). In these cells, higher levels of PTEN (Fig. 5B) and lower levels of p-Akt (Fig. 5D) were also detected. In contrast, cells transfected with the negative control siRNA did not show any significant changes in the expression of these three proteins compared to the untransfected Hep-2 cells ( $\mathrm{P}>0.05)$.

We then turned to investigate if EphA7 siRNA could regulate the expression of PTEN/ Akt downstream apoptotic proteins in Hep-2 cells. Concomitantly, western blotting analysis showed that EphA7 siRNA could down-regulate the expression of anti-apoptotic protein Bcl2 (Fig. 5E) and up-regulate the expression of Bax (Fig. 5F) and Caspase-3 (Fig. 5G) in Hep2 cells compared with the negative control siRNA or untransfected cells. Furthermore, the same results were reproduced in another cell line AMC-HN-8 cells. In the Figure 6, we also 


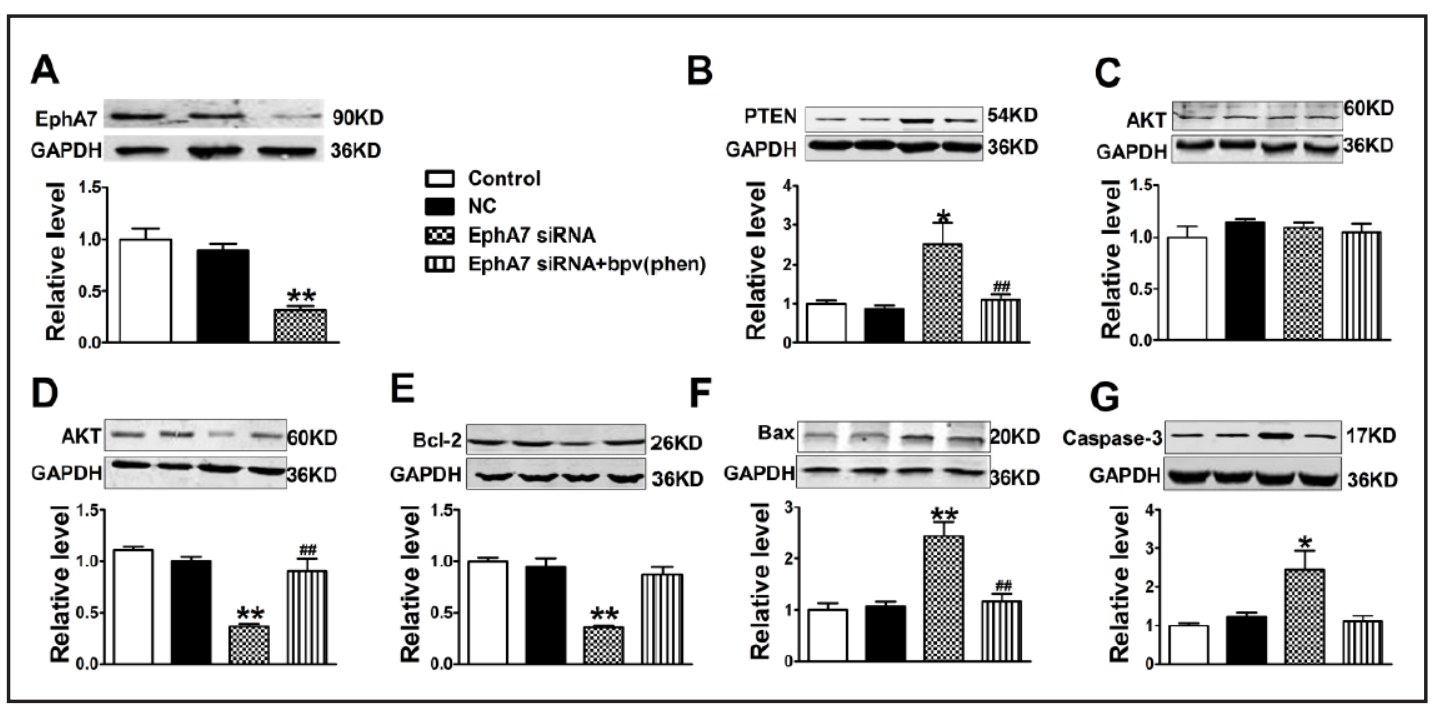

Fig. 5. Silencing of EphA7 by siRNA influences the expression levels of EphA7, PTEN, p-Akt and Akt in cultured Hep-2 cells. (A-D) Protein levels of EphA7, PTEN, Akt and p-Akt in different treatment groups. EphA7 siRNA influences the expression of the apoptosis-related proteins Bcl-2, Bax and Caspase-3 in Hep-2 cells. Quantitative analysis of Bcl-2 (E), Bax (F) and Caspase-3 (G) expression in Hep-2 cells in different treatment groups by western blotting. GAPDH was used as an internal control. Data are expressed as mean $\pm \mathrm{SEM}, \mathrm{n}=4$, ${ }^{* *} \mathrm{P}<0.01$ vs Control group, ${ }^{\# \#} \mathrm{P}<0.01$ vs EphA7 siRNA group.

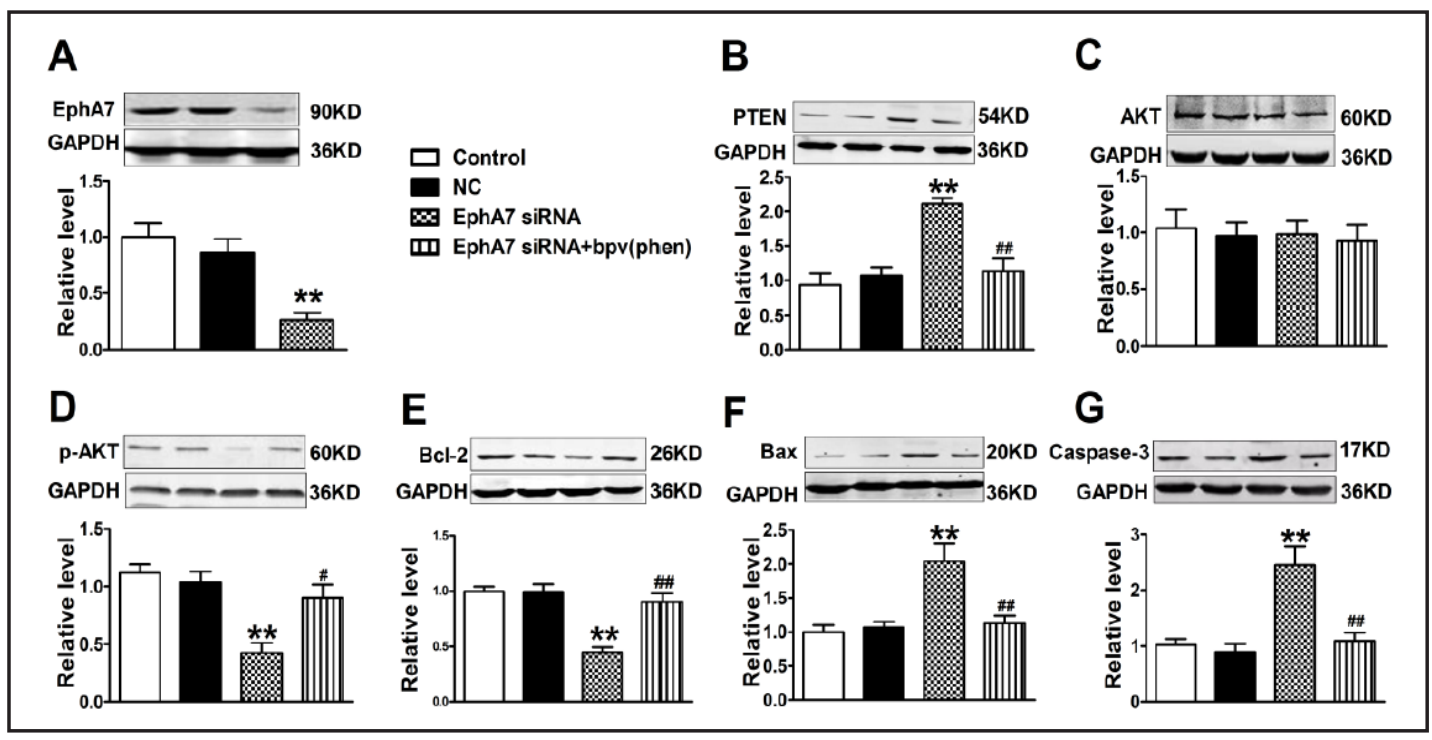

Fig. 6. Silencing of EphA7 by siRNA influences the expression levels of EphA7, PTEN, p-Akt and Akt in cultured AMC-HN-8 cells. (A-D) Protein levels of EphA7, PTEN, Akt and p-Akt in different treatment groups. EphA7 siRNA influences the expression of the apoptosis-related proteins Bcl-2, Bax and Caspase-3 in AMCHN-8 cells. Quantitative analysis of Bcl-2 (E), Bax (F) and Caspase-3 (G) expression in AMC-HN-8 cells in different treatment groups by western blotting. GAPDH was used as an internal control. Data are expressed as mean \pm SEM, $n=4,{ }^{* *} \mathrm{P}<0.01$ vs Control group; ${ }^{\#} \mathrm{P}<0.05$, \#\# $\mathrm{P}<0.01$ vs EphA7 siRNA group.

found that higher levels of PTEN (Fig. 6B) and lower levels of p-Akt (Fig. 6D) were detected in cells transfected with EphA7 siRNA. And EphA7 siRNA could also down-regulate the expression of anti-apoptotic protein Bcl-2 (Fig. 6E) and up-regulate the expression of Bax (Fig. 6F) and Caspase-3 (Fig. 6G) in AMC-HN-8 cells compared with the negative control siRNA or untransfected cells. However, pre-treated with bpV(phen), a PTEN inhibitor, could KARGER 


\section{Cellular Physiology Cell Physiol Biochem 2015;36:435-445 \\ \begin{tabular}{l|l} 
and Biochemistry Published online: May 11, 2015 & $\begin{array}{l}\text { C) 2015 S. Karger AG, Basel } \\
\text { www.karger.com/cpb }\end{array}$ \\
\hline
\end{tabular} \\ Xiang et al.: Effect of EphA7 Silencing on Human Laryngeal Cancer Cells}

attenuate the pro-apoptotic function of EphA7 siRNA in Hep-2 or AMC-HN-8 cells. Taken together, these results suggest that EphA7 siRNA can markedly induce apoptosis in Hep-2 or AMC-HN-8 cells through the inhibition of PTEN/Akt signaling pathway.

\section{Discussion}

The present study yielded several novel findings. First, we found, for the first time, that up-regulation of EphA7 in human LSCC tissues. In an in vitro study we found that EphA7 siRNA could markedly knockdown EphA7 expression in LSCC cell line Hep-2 or AMC-HN-8 cells. And knockdown of EphA7 in LSCC cell line Hep-2 or AMC-HN-8 cells could significantly induce cell apoptosis and suppress the invasion and migration. Moreover, our data strongly suggested that suppression of EphA7 in LSCC cell line Hep-2 or AMC-HN-8 mediated cells proliferation, invasion and apoptosis via regulating the expression of downstream signal proteins PTEN/Akt in vitro. These findings not only help us disclose the mechanisms of EphA7 in regulating the proliferation, invasion and apoptosis in LSCC cell line Hep-2 or AMC-HN-8 but also conceptually advance our view of siRNA that may serve as potential therapeutic and drug targets.

Human EphA7 was isolated from a human fetal brain library and found to be distributed widely in human tissues $[23,24]$. Of the Eph family genes, less attention has been directed to EphA7 in human tumors, and its potential role in human oncology has not been addressed. In a recent study, Wang et al. described the differential expression of EphA7 in gastric carcinoma samples and the correlation between EphA7 expression and clinicopathologic features [25]. They performed immunohistochemical staining for EphA7 in 52 gastric carcinoma specimens and found that expression of the protein was consistent with its transcript expression, with the protein being significantly overexpressed in younger patients and in patients with advanced tumors. These data indicate that EphA7 may have roles in the pathogenesis and development of gastric carcinomas [25]. In addition, An et al. demonstrated that the immunohistochemical assessment of tissue EphA7 provided important prognostic information in glioblastoma multiforme patients, which would justify its use as surrogate marker to screen patients for tyrosine kinase inhibitor therapy [26]. Recent study showed that the mRNA of EphA7 was strongly upregulated in hepatocellular carcinoma as compared with healthy liver tissue and was downregulated in colon carcinomas. And EphA7 is also transcriptionally activated in lung cancer [27]. Consistent with previous research, data from this study also disclosed that EphA7 was over-expressed in human LSCC in vivo.

Although Eph receptors have been implicated in regulating apoptotic cell death, the molecular mechanism by which Eph signaling is linked with the apoptotic signaling cascade is poorly understood [28]. In a recent study, Miranda et al. identified EphA7 receptors as putative regulators of apoptosis in the acute phase after spinal cord injury [29]. The results presented in this study provided biochemical evidence for the possibility that knockdown of EphA7 in human LSCC cell line Hep-2 or AMC-HN-8 could trigger the cell apoptosis via regulating the PTEN/Akt signaling pathway. When Hep-2 cells or AMC-HN-8 were transfected with the EphA7 siRNA, lower levels of EphA7 were detected compared to cells transfected with the negative control siRNA or untransfected cells. Concomitantly, in these cells, higher levels of PTEN and lower p-Akt expression were also detected. Furthermore, we further demonstrated that EphA7 siRNA could down-regulate the expression of antiapoptotic protein $\mathrm{Bcl}-2$ and up-regulate the expression of Bax and Caspase- 3 in Hep-2 cells or AMC-HN-8 cells.

Taken together, in this study we identified that over-expression of EphA7 in human LSCC tissues. In vitro knockdown of EphA7 expression in human LSCC cell line Hep-2 or AMC-HN-8 cells was able to effectively suppress cell proliferation, migration, invasion, and promote cell apoptosis. And we also explore the role of the EphA7 in the regulation of Hep2 cells or AMC-HN-8 cells apoptosis via PTEN/Akt signaling pathway in vitro. Thus, EphA7 has a critical role in modulating cell growth, migration and apoptosis, which can serve as a potential therapeutic target in human LSCC treatment. 


\section{Cellular Physiology Cell Physiol Biochem 2015;36:435-445 \begin{tabular}{ll|l} 
and Biochemistry & $\begin{array}{l}\text { DOI: 10.1159/000430110 } \\
\text { Published online: May 11, } 2015\end{array}$ & $\begin{array}{l}\text { C 2015 S. Karger AG, Basel } \\
\text { www.karger.com/cpb }\end{array}$ \\
\hline
\end{tabular} \\ Xiang et al.: Effect of EphA7 Silencing on Human Laryngeal Cancer Cells}

\section{Acknowledgements}

We thank all members of our laboratory for helpful discussions and comments on the manuscript.

\section{Disclosure Statement}

The authors confirm that there are no conflicts of interest.

\section{References}

1 Choong N, Vokes E: Expanding role of the medical oncologist in the management of head and neck cancer. CA Cancer J Clin 2008;58:32-53.

2 Li F, Liu Y, Kan X, Li Y, Liu M, Lu JG: Elevated expression of integrin alphav and beta5 subunit in laryngeal squamous-cell carcinoma associated with lymphatic metastasis and angiogenesis. Pathol Res Pract 2013;209:105-109.

3 Weller P, Bankfalvi A, Gu X, Dominas N, Lehnerdt GF, Zeidler R, Lang S, Brandau S, Dumitru CA: The role of tumour foxp3 as prognostic marker in different subtypes of head and neck cancer. Eur J Cancer 2014;50:1291-1300.

4 Luo HN, Wang ZH, Sheng Y, Zhang Q Yan J, Hou J, Zhu K, Cheng Y, Xu YL, Zhang XH, Xu M, Ren XY: Mir-139 targets cxcr4 and inhibits the proliferation and metastasis of laryngeal squamous carcinoma cells. Med Oncol 2014;31:789.

5 Janes PW, Griesshaber B, Atapattu L, Nievergall E, Hii LL, Mensinga A, Chheang C, Day BW, Boyd AW, Bastiaens PI, Jorgensen C, Pawson T, Lackmann M: Eph receptor function is modulated by heterooligomerization of a and b type eph receptors. J Cell Biol 2011;195:1033-1045.

6 Aitsebaomo J, Portbury AL, Schisler JC, Patterson C: Brothers and sisters: Molecular insights into arterialvenous heterogeneity. Circ Res 2008;103:929-939.

7 Steinecke A, Gampe C, Zimmer G, Rudolph J, Bolz J: Epha/ephrin a reverse signaling promotes the migration of cortical interneurons from the medial ganglionic eminence. Development 2014;141:460-471.

8 Reissenweber B, Mosch B, Pietzsch J: Experimental hypoxia does not influence gene expression and protein synthesis of eph receptors and ephrin ligands in human melanoma cells in vitro. Melanoma Res 2013;23:85-95.

9 Jang BG, Lee BL, Kim WH: Distribution of lgr5+ cells and associated implications during the early stage of gastric tumorigenesis. PloS One 2013;8:e82390.

10 Yu G, Gao Y, Ni C, Chen Y, Pan J, Wang X, Ding Z, Wang J: Reduced expression of ephb2 is significantly associated with nodal metastasis in chinese patients with gastric cancer. J Cancer Res Clin Oncol 2011;137:73-80.

11 Chukkapalli S, Amessou M, Dilly AK, Dekhil H, Zhao J, Liu Q, Bejna A, Thomas RD, Bandyopadhyay S, Bismar TA, Neill D, Azoulay L, Batist G, Kandouz M: Role of the ephb2 receptor in autophagy, apoptosis and invasion in human breast cancer cells. Exp Cell Res 2014;320:233-246.

12 Batson J, Maccarthy-Morrogh L, Archer A, Tanton H, Nobes CD: Epha receptors regulate prostate cancer cell dissemination through vav2-rhoa mediated cell-cell repulsion. Biol Open 2014;3:453-462.

13 Brantley-Sieders DM, Dunaway CM, Rao M, Short S, Hwang Y, Gao Y, Li D, Jiang A, Shyr Y, Wu JY, Chen J: Angiocrine factors modulate tumor proliferation and motility through epha2 repression of slit2 tumor suppressor function in endothelium. Cancer Res 2011;71:976-987.

14 Miyazaki T, Kato H, Kimura H, Inose T, Faried A, Sohda M, Nakajima M, Fukai Y, Masuda N, Manda R, Fukuchi M, Tsukada K, Kuwano H: Evaluation of tumor malignancy in esophageal squamous cell carcinoma using different characteristic factors. Anticancer Res 2005;25:4005-4011.

15 Huusko P, Ponciano-Jackson D, Wolf M, Kiefer JA, Azorsa DO, Tuzmen S, Weaver D, Robbins C, Moses T, Allinen M, Hautaniemi S, Chen Y, Elkahloun A, Basik M, Bova GS, Bubendorf L, Lugli A, Sauter G, Schleutker J, Ozcelik H, Elowe S, Pawson T, Trent JM, Carpten JD, Kallioniemi OP, Mousses S: Nonsense-mediated decay microarray analysis identifies mutations of ephb2 in human prostate cancer. Nat Genet 2004;36:979-983. 


\section{Cellular Physiology Cell Physiol Biochem 2015;36:435-445

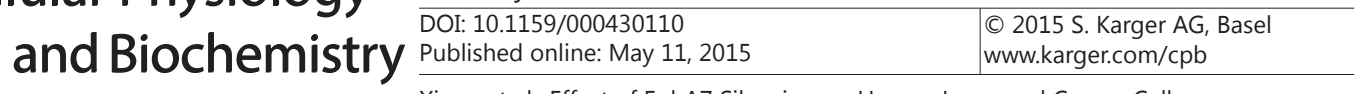 \\ Xiang et al.: Effect of EphA7 Silencing on Human Laryngeal Cancer Cells}

16 Davalos V, Dopeso H, Velho S, Ferreira AM, Cirnes L, Diaz-Chico N, Bilbao C, Ramirez R, Rodriguez G, Falcon O, Leon L, Niessen RC, Keller G, Dallenbach-Hellweg G, Espin E, Armengol M, Plaja A, Perucho M, Imai K, Yamamoto H, Gebert JF, Diaz-Chico JC, Hofstra RM, Woerner SM, Seruca R, Schwartz S Jr, Arango D: High ephb2 mutation rate in gastric but not endometrial tumors with microsatellite instability. Oncogene 2007;26:308-311.

17 Taneja R, Thisse B, Rijli FM, Thisse C, Bouillet P, Dolle P, Chambon P: The expression pattern of the mouse receptor tyrosine kinase gene $\mathrm{mdk} 1$ is conserved through evolution and requires hoxa- 2 for rhombomerespecific expression in mouse embryos. Dev Biol 1996;177:397-412.

18 Stanic K, Vera A, Gonzalez M, Recabal A, Astuya A, Torrejon M, Montecinos H, Caprile T: Complementary expression of epha7 and sco-spondin during posterior commissure development. Front Neuroanat 2014;8:49.

19 Lee H, Park E, Kim Y, Park S: Ephrina5-epha7 complex induces apoptotic cell death via tnfr1. Mol Cells 2013;35:450-455.

20 Oricchio E, Wendel HG: Mining the cancer genome uncovers therapeutic activity of epha7 against lymphoma. Cell Cycle 2012;11:1076-1080.

21 Tu Y, Wan L, Fan Y, Wang K, Bu L, Huang T, Cheng Z, Shen B: Ischemic postconditioning-mediated mirna-21 protects against cardiac ischemia/reperfusion injury via pten/akt pathway. PloS One 2013;8:e75872.

22 Han G, Wang Y, Bi W, Jia J, Wang W: Microrna-124 functions as a tumor suppressor and indicates prognosis in human osteosarcoma. Exp Ther Med 2015;9:679-684.

23 Sefton M, Nieto MA: Multiple roles of eph-like kinases and their ligands during development. Cell Tissue Res 1997;290:243-250.

24 Hafner C, Schmitz G, Meyer S, Bataille F, Hau P, Langmann T, Dietmaier W, Landthaler M, Vogt T: Differential gene expression of eph receptors and ephrins in benign human tissues and cancers. Clin Chem 2004;50:490-499.

25 Wang J, Li G, Ma H, Bao Y, Wang X, Zhou H, Sheng Z, Sugimura H, Jin J, Zhou X: Differential expression of epha7 receptor tyrosine kinase in gastric carcinoma. Hum Pathol 2007;38:1649-1656.

26 Wang LF, Fokas E, Juricko J, You A, Rose F, Pagenstecher A, Engenhart-Cabillic R, An HX: Increased expression of epha7 correlates with adverse outcome in primary and recurrent glioblastoma multiforme patients. BMC Cancer 2008;8:79.

27 Surawska H, Ma PC, Salgia R: The role of ephrins and eph receptors in cancer. Cytokine Growth Factor Rev 2004;15:419-433.

28 Garcia-Ceca J, Alfaro D, Montero-Herradon S, Zapata AG: Eph/ephrinb signalling is involved in the survival of thymic epithelial cells. Immunol Cell Biol 2013;91:130-138.

29 Figueroa JD, Benton RL, Velazquez I, Torrado AI, Ortiz CM, Hernandez CM, Diaz JJ, Magnuson DS, Whittemore SR, Miranda JD: Inhibition of epha7 up-regulation after spinal cord injury reduces apoptosis and promotes locomotor recovery. J Neurosci Res 2006;84:1438-1451. 


\section{Erratum}

In the article by Xiang et al., entitled "Effect of EphA7 Silencing on Proliferation, Invasion and Apoptosis in Human Laryngeal Cancer Cell Lines Hep-2 and AMC-HN-8" [Cell Physiol Biochem 2015;36:435-445 (DOI: 10.1159/000430110)], legend of Figure 4 is wrong and should be changed into:

Fig. 4. EphA7 siRNA inhibits the migration and invasion of cultured Hep-2 or AMC-HN-8 cells. (A-B) Photographs represented the Hep-2 and AMC-HN-8 cells travelled through the membrane by Transwell assay and the cells passing through the Matrigel by Matrigel invasion assay (original magnification, $\times 200$ ). (C) The histogram showed the number of migrated Hep-2 cells. (D) The histogram showed the number of invaded Hep-2 cells. (E) The histogram showed the number of migrated AMC-HN-8 cells. (F) The histogram showed the number of invaded AMC-HN-8 cells. Data are expressed as mean $\pm \mathrm{SEM}, \mathrm{n}=3 ;{ }^{* *} \mathrm{P}<0.01$ /vs / Control.

The authors sincerely apologize for this error. 